\title{
IRPD Spectroscopy and Ensemble Measurements: Effects of Different Data Acquisition and Analysis Methods
}

\author{
James S. Prell, Jeremy T. O’Brien, and Evan R. Williams \\ Department of Chemistry, University of California, Berkeley, California, USA
}

Three different commonly used infrared photodissociation (IRPD) spectroscopy acquisition and analysis methods are described, and results from these methods are compared using the same dataset for an extensively hydrated metal cation, $\mathrm{La}^{3+}\left(\mathrm{H}_{2} \mathrm{O}\right)_{36}$. Using the first-order laser-induced photodissociation rate constant as an IRPD intensity has several advantages over photodissociation yield and depletion/appearance methods in that intensities can be more directly compared with calculated infrared absorption spectra, and the intensities can be readily corrected for changes in laser power or irradiation times used for optimum data acquisition at each frequency. Extending IRPD spectroscopy to large clusters can be complicated when blackbody infrared radiative dissociation competes strongly with laser-induced photodissociation. A new method to obtain IRPD spectra of single precursor ions or ensembles of precursor ions that is nearly equivalent to the photodissociation rate constant method for single precursor ions is demonstrated. The ensemble IRPD spectra represent the "average" structure of clusters of a given size range, and this method has the advantage that spectra with improved signal-to-noise ratios can be obtained with no increase in data acquisition time. Results using this new method for a precursor ensemble consisting of $\mathrm{La}^{3+}\left(\mathrm{H}_{2} \mathrm{O}\right)_{35-37}$ are compared with results for $\mathrm{La}^{3+}\left(\mathrm{H}_{2} \mathrm{O}\right)_{36}$. (J Am Soc Mass Spectrom 2010, 21, 800-809) ( 2010 Published by Elsevier Inc. on behalf of American Society for Mass Spectrometry

$I^{3}$ n infrared photodissociation (IRPD) spectroscopy, an "action" spectrum of an ion is often obtained by measuring the extent of dissociation after exposure to laser radiation as a function of photon energy. Intense, tunable radiation in the mid-IR region $(\sim 100-$ $2500 \mathrm{~cm}^{-1}$ ) can be generated at the free electron laser facilities, FELIX [1] and CLIO [2], which facilitates application of this method to large or very stable ions. Lower-intensity tunable radiation in the $\sim 600-4100$ $\mathrm{cm}^{-1}$ range from tabletop laser systems has also been used in IRPD spectroscopy as well as related conformerselective spectroscopies, and these systems have the advantage that they are relatively inexpensive, making them accessible to many laboratories [3-21]. Interest in IRPD spectroscopy has increased significantly in the last several years, and over 50 peer-reviewed papers were published in 2008. Typical instrumentation, chemical systems studied, and the variety of structural information obtained using IRPD spectroscopy have been reviewed recently [3, 22-24].

Depending on the initial internal energy of the precursor ion and the dissociation energy, the absorption of multiple photons may be necessary to induce dissociation of the precursor ion on the timescale of the

Address reprint requests to Dr. E. R. Williams, Department of Chemistry, University of California, Berkeley, 94720-1460, USA. E-mail: williams@ cchem.berkeley.edu experiment. Under conditions where the initial ion internal energy is much lower than that necessary to produce fragmentation on the timescale of the experiment, the absorption of several photons is necessary to preheat the ion before observable photodissociation occurs [24-28], resulting in a power-dependent "induction period" in the photodissociation kinetics [25, 26], as illustrated schematically in Figure 1. For such ions, photodissociation occurs as a consequence of many sequential ("multiple photon") or simultaneous ("multiphoton") absorption events, although multiple photon dissociation is usually much more favorable [3]. The IR(M)PD spectra obtained for such ions can exhibit substantial differences from calculated absorption spectra, including frequency shifts and discrepant intensities $[4,24,29-32]$. When the initial ion internal energy is sufficient for dissociation to occur, or for small ions with low threshold dissociation energies, absorption of ambient blackbody photons can induce dissociation [33, 34]. The absorption of even a single infrared photon can increase the rate of dissociation for such ions. Under these conditions, there will be no induction period (Figure 1), so that IRPD spectra will more closely resemble true linear absorption spectra. For ions that have two (or more) conformers that do not interconvert on the time scale of the experiment but have unique IRPD spectra, the dissociation kinetics can be bi- (or multi-) exponential. The individual spectrum of each
(C) 2010 Published by Elsevier Inc. on behalf of American Society for Mass Spectrometry. 1044-0305/10/\$32.00

doi:10.1016/j.jasms.2010.01.010
Published online January 25, 2010 Received November 12, 2009 Revised January 6, 2010 Accepted January 10, 2010 


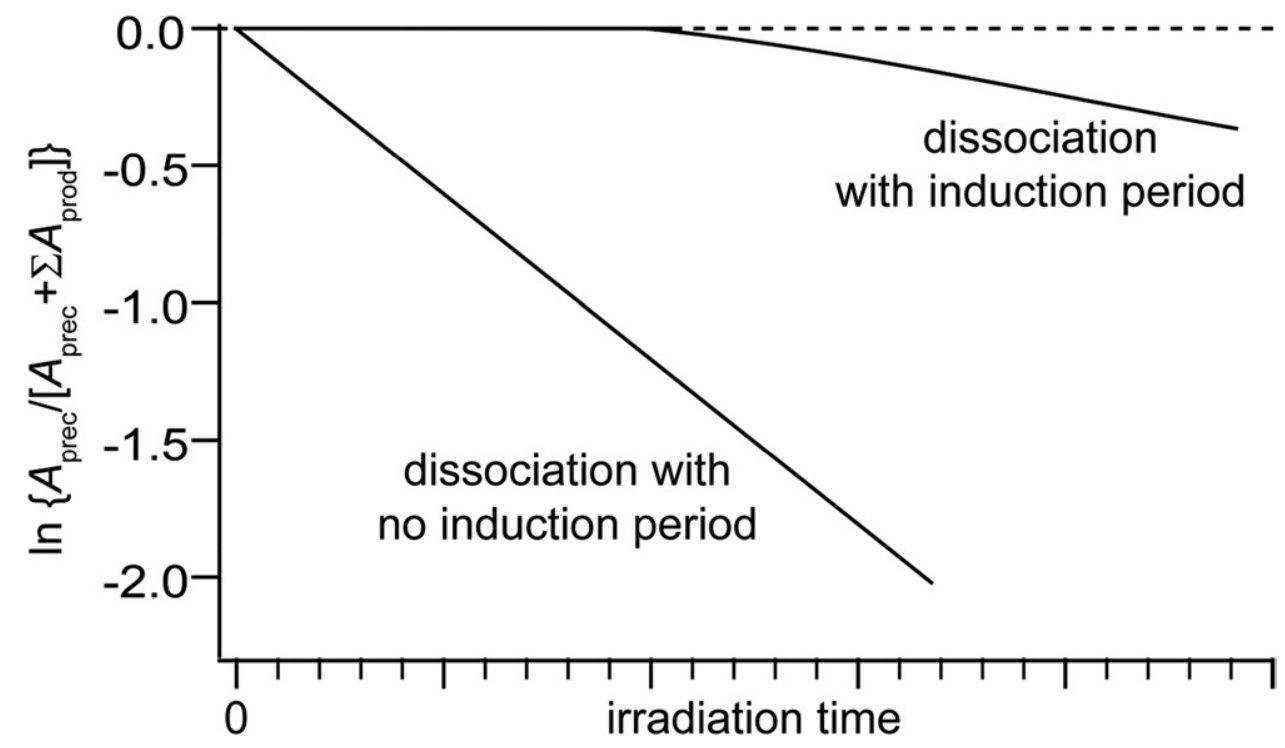

Figure 1. Illustration of laser-induced photodissociation kinetics for a precursor ion with initial internal energy much lower than that necessary to produce fragmentation on the timescale of the experiment, resulting in an induction period; and a small precursor ion with a low threshold dissociation energy or an ion for which the initial internal energy is sufficient for dissociation to occur with no induction period.

conformer can, in principle, be obtained from the individual rate constants obtained from fitting the kinetic data.

Three primary methods have been used to determine a dissociation intensity to be used in plotting the IRPD spectrum from the fragment and/or precursor abundances. One of the most commonly used methods to determine an IRPD intensity is to calculate a "photodissociation yield" (PDY), defined by

$$
\begin{aligned}
\operatorname{PDY}\left(t_{i r r}, \hbar \omega\right)= & {\left[\sum A_{\text {frag }}\left(t_{i r r}, \hbar \omega\right)\right] /\left[A_{\text {prec }}\left(t_{\text {irr }}, \hbar \omega\right)\right.} \\
& \left.+\sum A_{\text {frag }}\left(t_{i r r}, \hbar \omega\right)\right]
\end{aligned}
$$

where $\Sigma A_{\text {frag }}$ is the sum of all detected fragment abundances and $A_{\text {prec }}$ is the precursor abundance measured after photodissociation for a time $t_{i r}$ with photons of energy $\hbar \omega$. Because the PDY depends on a ratio of correlated abundances, it does not depend on fluctuations in initial precursor population from scan to scan. This is the method currently used for the majority of IRPD spectra obtained using FELIX [31, 32, 35-40], including many tightly-bound complexes for which the absorption of many mid-infrared photons is typically necessary to induce fragmentation.

An action spectrum can also be obtained by measuring the extent of depletion of the precursor ion or appearance of a fragment ion. This is typically done when fragment and precursor abundances cannot be measured simultaneously, as for experiments without multichannel detection [8, 41], or where fragment abundances have very poor signal-to-noise $(\mathrm{S} / \mathrm{N})$ due to the presence of many competitive dissociation channels $[42,43]$. In such cases, a "depletion spec- trum" or "appearance spectrum" can be measured with respect to a reference value in the absence of laser irradiation $\left(A_{\text {prec/frag }}^{*}\right)$ :

$$
\begin{gathered}
\text { depletion/appearance }\left(t_{i r r}, \hbar \omega\right) \\
=A_{\text {precfrag }}^{*}-A_{\text {precfrag }}\left(t_{i r r}, \hbar \omega\right)
\end{gathered}
$$

A significant disadvantage of this method is that the spectrum can be source-noise limited due to the potentially poor reproducibility of $A_{\text {prec/frag. This effect can }}^{*}$ often be reduced by re-measuring $A_{\text {prec/frag }}^{*}$ frequently and/or by signal averaging if the fluctuations in $A_{\text {prec/frag }}^{*}$ are random.

An alternative to these methods is to use the photodissociation rate constant of the precursor ion as the IRPD intensity. Laser-induced photodissociation of precursor complexes often follows first-order kinetics, if laser power is not so high as to favor multi-photon processes, although this first-order kinetic behavior may be preceded by an induction period during which the ions are preheated without producing observable fragmentation [24-26]. If photodissociation is rapid, single photon absorption becomes the rate-limiting step in the IRPD process, resulting in first-order laser photodissociation rate constants, $k_{\text {laser }}(\hbar \omega)$, after the induction period that can be proportional to the linear absorption cross section of the precursor. When the initial ion internal energy is high, or for small ions with low threshold dissociation energies, BIRD may be observed on the timescale of the experiment, and laser photodissociation kinetics do not show an induction period [44]. In this case, BIRD occurs with a fixed rate constant, $k_{B I R D}$, independent of laser photon energy, so 
that the observed first-order dissociation rate constant $k_{\text {IRPD }}$ is a sum of $k_{\text {laser }}(\hbar \omega)$ and $k_{B I R D}$. The value of $k_{B I R D}$ is thus found by measuring the IRPD rate constant

$$
\begin{aligned}
& k_{\text {IRPD }}(\hbar \omega)=k_{\text {BIRD }}+k_{\text {laser }}(\hbar \omega) \\
&=- \ln \left\{A_{\text {prec }}\left(t_{\text {irr }}, \hbar \omega\right) /\left[A_{\text {prec }}\left(t_{\text {irr }}, \hbar \omega\right)\right.\right. \\
&\left.\left.+\sum A_{\text {frag }}\left(t_{\text {irr }}, \hbar \omega\right)\right]\right\} / t_{\text {irr }}
\end{aligned}
$$

in the absence of laser irradiation, and $k_{\text {laser }}(\hbar \omega)$ is simply $k_{I R P D}(\hbar \omega)-k_{B I R D}$.

This $k_{\text {laser }}$ method has the advantage that the IRPD spectra are more directly comparable to calculated linear absorption spectra than the PDY and depletion/ appearance methods. The $k_{\text {laser }}$ method has been implemented to determine IRPD intensities for many hydrated ion complexes [44-49] as well as metal-cationized or protonated biomolecules [4] and protonated biomolecule dimers [50] in the hydrogen-stretch region $\left(\sim 2500-3800 \mathrm{~cm}^{-1}\right)$ and for a variety of ions in the $\sim 1000-2200 \mathrm{~cm}^{-1}$ region using the free electron laser CLIO [28, 51-55]. Note that $k_{I R P D}(\hbar \omega)$ itself is a one-toone but nonlinear function of the $\operatorname{PDY}\left(t_{i r r}, \hbar \omega\right)$ after any induction period. Thus, spectra plotted using either $k_{I R P D}(\hbar \omega)$ or $\operatorname{PDY}\left(t_{i r r}, \hbar \omega\right)$ contain, in principle, exactly the same information if the induction period is properly taken into account. PDY and depletion/appearance intensities depend on irradiation time, which cannot be adjusted over the course of the experiment without assuming a kinetic model for photodissociation. In contrast, the IRPD rate constant is independent of irradiation time under conditions where there is no induction period or for times after an induction period, so that irradiation times and consequently the extent of precursor depletion can be adjusted as the spectra are acquired to optimize the $S / N$ of the IRPD spectrum over all spectral regions. Because IRPD spectra are often compared with calculated $[15,20,28,35,39,41,49,53$, 56-65] or even experimental [66] linear absorption spectra, this method offers a distinct advantage over the PDY and depletion methods under these conditions.

All of the above methods have been used to investigate a wide range of ion structures, including closely related isomers, such as charge-solvated versus saltbridge structures $[4,30,31,35,43,45,56,60,61,67-76]$ or even ions whose gas-phase deprotonation site depends on the solvent from which the ions are formed [77]. Here, the utility of the above methods in obtaining IRPD spectra is compared for large hydrated ions, for which no induction period is observed in the photodissociation kinetics and for which $k_{B I R D}$ can be of the same order as $k_{\text {laser }}(\hbar \omega)$ at the laser power available in common table-top OPO/OPA systems. A new method for obtaining IRPD intensities of isolated ensembles of hydrated ions of similar size that is equivalent to the $k_{\text {laser }}(\hbar \omega)$ method for a single precursor is demonstrated. With this new method, IRPD spectra of large complexes can be acquired with better $\mathrm{S} / \mathrm{N}$ than by other methods in the same acquisition time, and "average" spectra for complexes of a given size range provide information about structural trends.

\section{Experimental}

IRPD spectra of hydrated $\mathrm{La}^{3+}\left(\mathrm{H}_{2} \mathrm{O}\right)_{36}$ and $\mathrm{La}^{3+}\left(\mathrm{H}_{2} \mathrm{O}\right)_{35-37}$ were acquired using a 2.75 Tesla Fourier transform ion cyclotron resonance mass spectrometer coupled to a tunable OPO/OPA laser system [4]. These hydrated ions are formed by nanoelectrospray ionization using borosilicate capillaries that are pulled to an i.d. of $\sim 1$ $\mu \mathrm{m}$ and are filled with a $5 \mathrm{mM}$ aqueous solution of $\mathrm{LaCl}_{3}$. A platinum wire is inserted into the capillary and held in direct contact with the solution at a potential of $\sim 600 \mathrm{~V}$ relative to the heated metal capillary of the electrospray interface. Ions are injected into the ion cell of the instrument through five stages of differential pumping using a series of electrostatic lenses. A copper block, cooled to $133 \mathrm{~K}$ by a temperature-regulated flow of liquid nitrogen, surrounds the ion cell and is equilibrated for at least $8 \mathrm{~h}$ before all experiments [78]. Trapping and thermalization of ions is enhanced with a $\sim 5 \mathrm{~s}$ pulse of dry nitrogen $\left(\sim 10^{-6}\right.$ Torr $)$ and a $\sim 12 \mathrm{~s}$ pumpdown to a pressure of $\sim 10^{-8}$ Torr. Precursor clusters are isolated using stored inverse Fourier transform waveforms.

Photodissociation is achieved by irradiating the isolated precursor ions with tunable light in the hydrogenstretch region $\left(\sim 2500-3800 \mathrm{~cm}^{-1}\right)$ from a table-top OPO/OPA laser system (LaserVision, Bellevue, WA, U.S.A.) pumped by the $1064 \mathrm{~cm}^{-1}$ fundamental of a Nd:YAG laser (Continuum Surelight I-10; Santa Clara, CA, U.S.A.) at a $10 \mathrm{~Hz}$ repetition rate. An irradiation time of $1.5 \mathrm{~s}$ is used to produce substantial but not complete fragmentation of the precursor ions on resonance with the laser irradiation. Precursor fragmentation due to blackbody infrared radiative dissociation (BIRD) in the absence of laser irradiation is re-measured every $\sim 15 \mathrm{~min}$ to monitor variability in precursor ion abundances. For each laser frequency used and for each BIRD measurement in IRPD spectroscopy experiments, five consecutive measurements are signal-averaged to obtain precursor and product ion abundances. For BIRD and laser kinetics experiments, ten consecutive measurements are signal-averaged for each irradiation time.

\section{Results and Discussion}

\section{IRPD Spectra of Individual Precursors}

Both BIRD and laser irradiation with photon energies between 2900 and $3800 \mathrm{~cm}^{-1}$ result exclusively in the sequential loss of water molecules from the precursor ions in these experiments. Exposure of $\mathrm{La}^{3+}\left(\mathrm{H}_{2} \mathrm{O}\right)_{36}$ to the $133 \mathrm{~K}$ blackbody field of the ion cell results in $\sim 16 \%$ dissociation after $1.5 \mathrm{~s}$ (Figure 2, top middle). Irradiating these ions with $3694 \mathrm{~cm}^{-1}$ light for this same time period results in loss of up to four water molecules, 

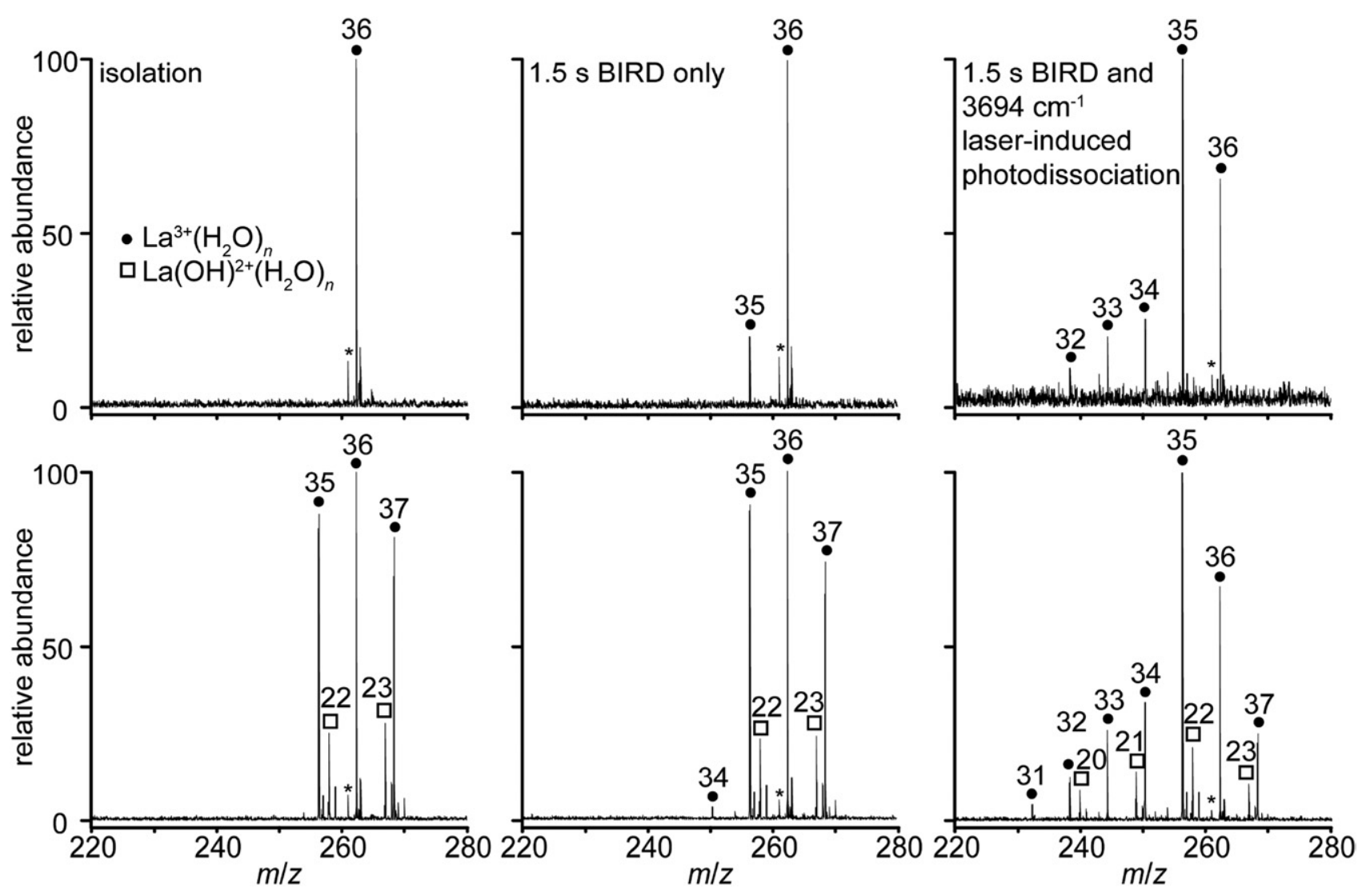

Figure 2. Mass spectra of $\mathrm{La}^{3+}\left(\mathrm{H}_{2} \mathrm{O}\right)_{36}$ (top) and the ensemble $\mathrm{La}^{3+}\left(\mathrm{H}_{2} \mathrm{O}\right)_{35-37}$ (bottom) at $133 \mathrm{~K}$ after initial isolation (left), after $1.5 \mathrm{~s}$ of BIRD (middle), and after $1.5 \mathrm{~s}$ irradiation with $3694 \mathrm{~cm}^{-1}$ light from a tunable OPO/OPA tabletop laser system (right). The asterisk indicates an instrumental noise peak. $\mathrm{La}(\mathrm{OH})^{2+}\left(\mathrm{H}_{2} \mathrm{O}\right)_{22,23}$ were not ejected to avoid exciting the $\mathrm{La}^{3+}\left(\mathrm{H}_{2} \mathrm{O}\right)_{35-37}$ ensemble. The higher S/N ratio for the ensemble mass spectra can be attributed to a variety of factors, including day-to-day variations in humidity, source conditions, etc.

corresponding to $\sim 77 \%$ dissociation due to BIRD and laser irradiation (Figure 2, top right). Laser-induced photodissociation for all precursor ions investigated follows first-order kinetics to at least $\sim 95 \%$ depletion of the precursor, indicating that the vast majority of precursor ions have orbits that intersect the laser beam. At the laser photon energy corresponding to the most extensive dissociation observed in the IRPD spectroscopy experiments $\left(3432 \mathrm{~cm}^{-1}\right)$, loss of up to 5 water molecules from $\mathrm{La}^{3+}\left(\mathrm{H}_{2} \mathrm{O}\right)_{36}$ after the $1.5 \mathrm{~s}$ irradiation period is observed, and $\sim 90 \%$ of the precursor population is dissociated due to BIRD and laser irradiation.

IRPD spectra of $\mathrm{La}^{3+}\left(\mathrm{H}_{2} \mathrm{O}\right)_{36}$ at $133 \mathrm{~K}$ with intensities calculated using the PDY, depletion, and $k_{\text {laser }}$ methods described in the Introduction are shown in Figure 3. To make the comparison between IRPD intensity calculation methods more transparent, corrections to IRPD abundances due to variations in laser power as a function of frequency are not included. Values of $A^{*}$ prec used in calculating the depletion correspond to the abundance of $\mathrm{La}^{3+}\left(\mathrm{H}_{2} \mathrm{O}\right)_{36}$ after $1.5 \mathrm{~s}$ of BIRD in the absence of laser irradiation, and this value is remeasured every $\sim 15 \mathrm{~min}$. The resulting updated value of $A_{\text {prec }}^{*}$ is used to calculate the depletion until the next
$A_{\text {prec }}^{*}$ is measured. The value of $k_{B I R D}$ is obtained from these data and used to calculate $k_{\text {laser }}$.

For very stable ions that do not dissociate without laser irradiation on the timescale of the experiment, preheating of the ion by the laser light before observable dissociation can occur $[24,25]$, which results in an "induction period" in the dissociation kinetics [25]. Photodissociation of ions under such conditions follows first-order kinetics only after the induction period (Figure 1). IRPD spectra obtained using $k_{\text {laser }}$ that do not take into account this induction period will not be directly comparable with linear absorption spectra. In contrast, for ions that dissociate readily due to BIRD, such as $\mathrm{La}^{3+}\left(\mathrm{H}_{2} \mathrm{O}\right)_{36}$ at $133 \mathrm{~K}$, absorption of even a single photon can be sufficient to increase the rate of dissociation, although absorption of more than one photon before dissociation may also occur. Dissociation kinetics for $\mathrm{La}^{3+}\left(\mathrm{H}_{2} \mathrm{O}\right)_{36}$ at $133 \mathrm{~K}$ in the absence of laser irradiation and with a laser photon energy of 3149 (off-resonance) or $3415 \mathrm{~cm}^{-1}$ (on-resonance) do not show an induction period (Figure 4).

It is clear from these IRPD spectra that both the PDY and depletion methods for calculating IRPD intensities introduce a substantial spectral band flattening from 


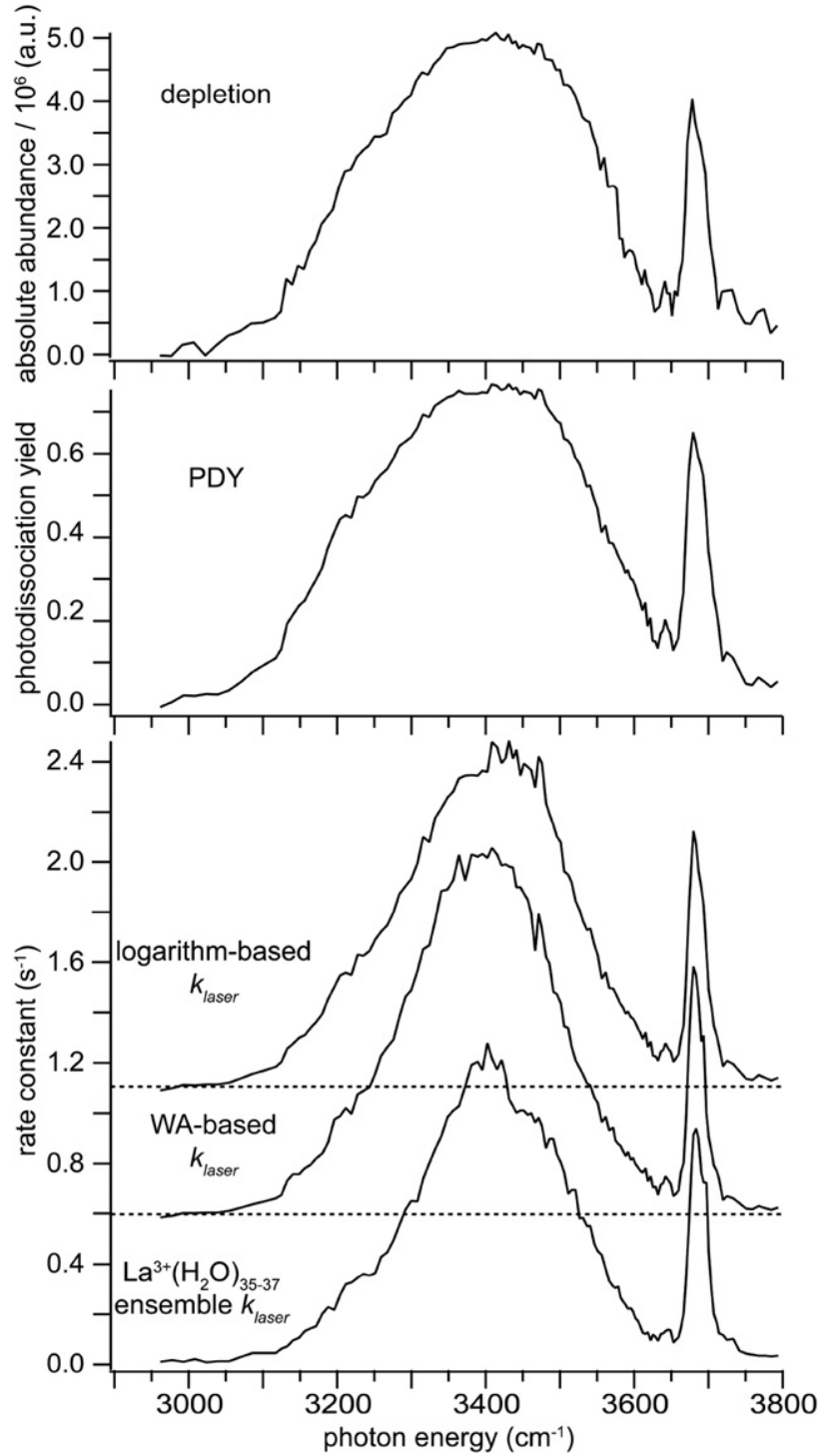

Figure 3. IRPD spectra of $\mathrm{La}^{3+}\left(\mathrm{H}_{2} \mathrm{O}\right)_{36}$ at $133 \mathrm{~K}$ obtained by calculating the extent of depletion, photodissociation yield (PDY), and first-order dissociation rate constant due to laser irradiation ( $k_{\text {laser }}$; baselines offset for clarity) based on the logarithm of the fraction of precursor population remaining or the weightedaverage method using the same photodissociation data. Also shown is the ensemble IRPD spectrum of $\mathrm{La}^{3+}\left(\mathrm{H}_{2} \mathrm{O}\right)_{35-37}$ at $133 \mathrm{~K}$.

$\sim 3300$ to $3500 \mathrm{~cm}^{-1}$ and from $\sim 3650$ to $3710 \mathrm{~cm}^{-1}$ (Figure 3). These bands correspond to hydrogenbonded and dangling $\mathrm{OH}$ oscillators, respectively [79]. Whereas two distinct bands have been reported between 3650 and $3710 \mathrm{~cm}^{-1}$ for hydrates of $\mathrm{La}^{3+}$ with between 17 and 20 water molecules [47], only a single feature is observed for $\mathrm{La}^{3+}\left(\mathrm{H}_{2} \mathrm{O}\right)_{36}$ using these methods. The IRPD spectrum derived from the precursor depletion is remarkably similar to the PDY due to the highly reproducible precursor abundance of $\mathrm{La}^{3+}\left(\mathrm{H}_{2} \mathrm{O}\right)_{36}$, which varied by less that $7 \%$ over the course of data acquisition. In the case that the precursor abundance does not vary at all and all ionic products have the same charge state as the precursor and are detected, the depletion should be essentially proportional to the PDY. In experiments where the ion abundance from the source fluctuates more dramatically, the spectra can be source-noise limited, and the agreement between the depletion and PDY or $k_{\text {laser }}$ IRPD spectra would be much worse.

The width of a spectral band in an ideal gas-phase linear absorption spectrum (where the absorption cross section is plotted against photon frequency) is largely related to physical attributes of the analyte, including rotational temperature and excited-state lifetime. The FWHM for the hydrogen-bonded $\mathrm{OH}$ band is $~ 50 \%$ greater using the PDY and depletion methods than for $k_{\text {laser }}$ and $\sim 40 \%$ greater for the dangling $\mathrm{OH}$ band. For the PDY, this phenomenon is an artifact of the relationship between $k_{I R P D}$ and the PDY:

$$
\operatorname{PDY}\left(t_{i r r}, \hbar \omega\right)=1-\exp \left(-k_{I R P D} \times t_{i r r}\right)
$$

whereby the PDY increases nonlinearly with $k_{I R P D}$ by ever smaller amounts. Because the spectral band widths increase with band intensity for the PDY method, this method cannot be used to obtain information about spectral band widths for intense features that is directly comparable to that from linear absorption spectroscopy. The broadening near the peak of intense features also unnecessarily decreases the apparent resolution in IRPD spectra with intense, overlapping spectral features relative to that obtained using $k_{\text {laser }}(\hbar \omega)$.

\section{Weighted-Average Ensemble IRPD Spectroscopy}

The better comparability of $k_{\text {laser }}(\hbar \omega)$ to linear absorption spectra under conditions where precursor ions dissociate readily and the ability to adjust $t_{i r r}$ in real time to optimize $\mathrm{S} / \mathrm{N}$ are major advantages of the logarithm-based $k_{\text {laser }}(\hbar \omega)$ in IRPD spectroscopy of hydrated clusters. However, extending this or other methods to very large clusters for which the ion lifetime is short and the $\mathrm{S} / \mathrm{N}$ is low can be challenging. BIRD rates generally increase with cluster size, so that photodissociation due to BIRD even at short irradiation times can be substantial for large clusters. For example, $k_{B I R D}$ for $\mathrm{La}^{3+}\left(\mathrm{H}_{2} \mathrm{O}\right)_{76}$ is $0.51 \pm 0.07 \mathrm{~s}^{-1}$ at $133 \mathrm{~K}$ (Figure 5), which corresponds to $\sim 40 \%$ depletion of the precursor ion in 1 s. Many ions or complexes absorb infrared laser radiation weakly enough that high laser power or multiple pulses $(>1 \mathrm{~s})$ of laser irradiation are required to induce significant photodissociation on the timescale of the experiment. If the BIRD rate is very high in such cases, the S/N of the IRPD spectra can be very poor. Signal averaging can improve the quality of IRPD spectra, but the $\mathrm{S} / \mathrm{N}$ gain scales with the square root of the number of scans. In contrast, by simultaneously photodissociating multiple precursors of similar size, the $\mathrm{S} / \mathrm{N}$ gain in an "average" IRPD spectrum should more directly scale with the number of precursors, i.e., $\mathrm{S} / \mathrm{N}$ gain can be achieved without increasing spectrum acquisition time. A new technique for acquiring and 


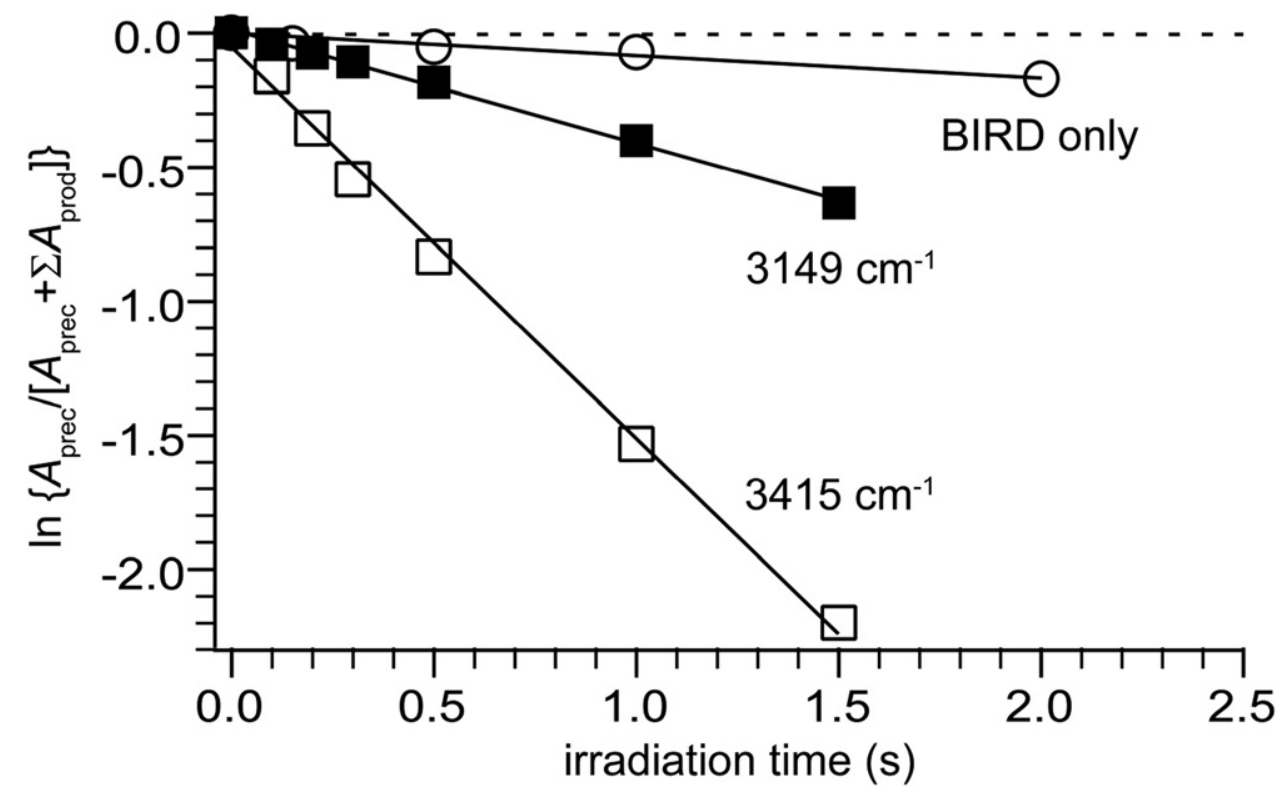

Figure 4. Dissociation kinetics for $\mathrm{La}^{3+}\left(\mathrm{H}_{2} \mathrm{O}\right)_{36}$ at $133 \mathrm{~K}$ due to blackbody infrared radiative dissociation (BIRD) alone (open circles) and with laser irradiation at photon energies of $3149 \mathrm{~cm}^{-1}$ (filled squares) and $3415 \mathrm{~cm}^{-1}$ (open squares).

analyzing IRPD spectra of large ensembles of hydrated clusters that exploits this advantage is described below.

The BIRD rate at a fixed temperature for large hydrated ion clusters typically increases approximately linearly as a function of the number of water molecules in the cluster, with minor deviations from linearity due to variations in water molecule binding energy or dissociation entropy or structural effects with cluster size. For a suitably narrow range of cluster sizes, the variation in the BIRD rate constants over that size range will be small compared to the average of their BIRD rates, i.e., $k_{B I R D}$ will be essentially constant over a narrow size range. This effect for $\mathrm{La}^{3+}\left(\mathrm{H}_{2} \mathrm{O}\right)_{n}, n$ between 29 and 76, is shown in Figure 5, in which $k_{B I R D}$ at $133 \mathrm{~K}$ is plotted as a function of cluster size. For example, the range of $k_{B I R D}$ values for $n$ between 34 and 37 is $\pm 22 \%$ of the mean value of $k_{B I R D}$ in this size range, and the average percent deviation of $k_{B I R D}$ from a least-squares fit to the data decreases with increasing $n$ to less than $12 \%$ for $n \geq 51$. Similarly, the linear absorption spectrum of sufficiently large hydrated ions should change little with cluster size, as has been observed for

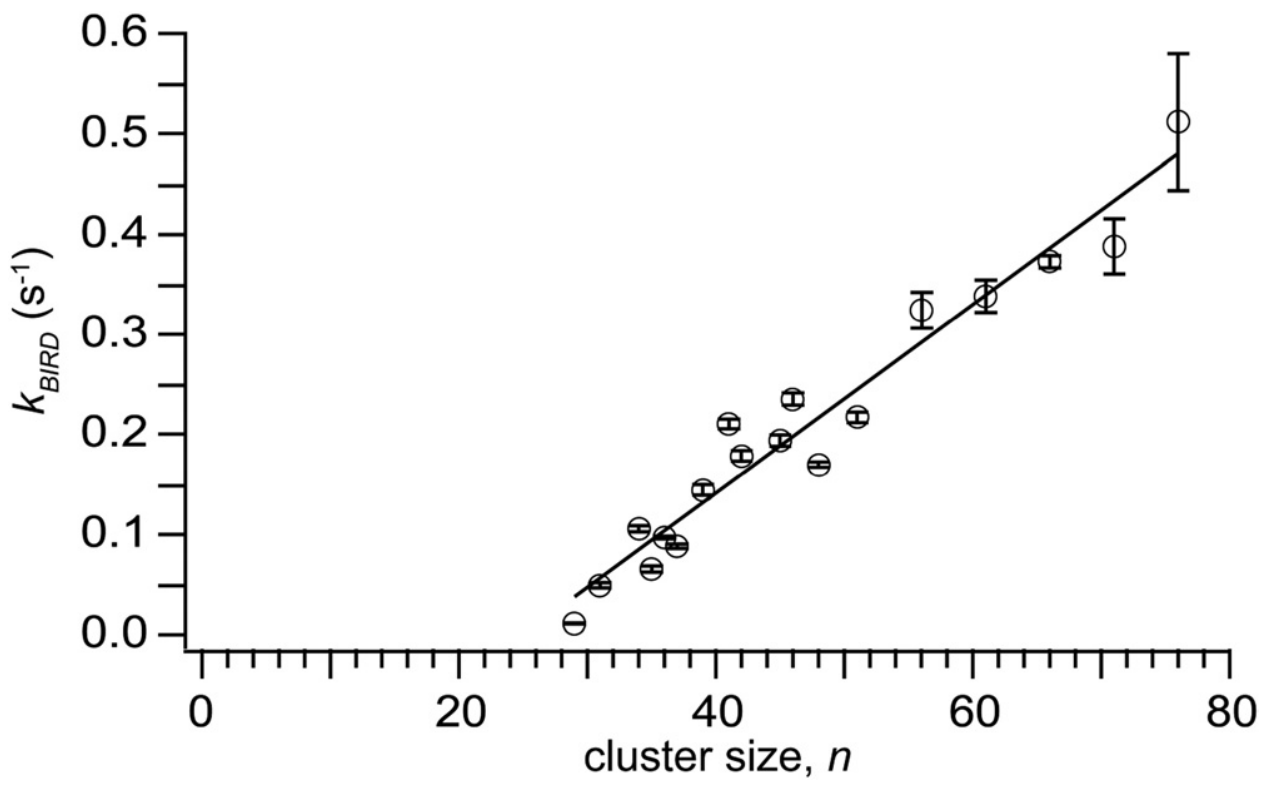

Figure 5. First-order blackbody infrared radiative dissociation (BIRD) rate constants at $133 \mathrm{~K}$ for $\mathrm{La}^{3+}\left(\mathrm{H}_{2} \mathrm{O}\right)_{n}, n$ between 29 and 76 , and a least-squares fit to the data. 
large neutral and protonated water clusters [80] and large hydrates of $\mathrm{Ca}^{2+}$ [48] and trivalent metal cations [47]. Thus, $k_{\text {laser }}$ (as well as $k_{I R P D}$ ) should be nearly constant over a suitably narrow range of cluster sizes.

The nearly constant values of $k_{\text {laser }}$ and $k_{B I R D}$ for large hydrated ions of similar cluster sizes motivate the introduction of a new method for calculating IRPD intensities that gives essentially the same result as the $k_{\text {laser }}$ method when a single precursor is isolated. In the following, we omit the subscript for the total first-order dissociation rate constant $k_{I R P D}$ (with or without laser irradiation) and hold the laser photon energy $\hbar \omega$ fixed for clarity. Suppose an ensemble of $(N+1)$ consecutive hydration states of an ion $A$ is isolated, with cluster sizes between $\left(n_{M A X}-N\right)$ and $n_{M A X}$. Let $A_{m}(t)$ be the abundance of the cluster with $\left(n_{M A X}-m\right)$ water molecules after a BIRD/laser irradiation time $t$, i.e., for the precursor ensemble $\mathrm{La}^{3+}\left(\mathrm{H}_{2} \mathrm{O}\right)_{35,36,37,} A_{0}(t)$ refers to the abundance at time $t$ of $\mathrm{La}^{3+}\left(\mathrm{H}_{2} \mathrm{O}\right)_{37}$, and $A_{m}(t)$ to the abundance of the $\mathrm{La}^{3+}\left(\mathrm{H}_{2} \mathrm{O}\right)_{37-m}$ cluster. Because each cluster dissociates by first-order kinetics with approximately the same rate constant by loss of one water molecule, we have the following system of kinetic equations:

$$
\begin{aligned}
& A_{0}(t)=A_{0}(0) e^{-k t} \\
& A_{1}(t)=A_{0}(0)(k t) e^{-k t}+A_{1}(0) e^{-k t} \\
& \vdots \quad \vdots \quad+\quad \vdots \quad+\ddots \\
& A_{N}(t)=A_{0}(0) \frac{(k t)^{N}}{N !} e^{-k t}+A_{1}(0) \frac{(k t)^{(N-1)}}{(N-1) !} e^{-k t}+\cdots+A_{N}(0) e^{-k t} \\
& A_{N+1}(t)=A_{0}(0) \frac{(k t)^{(N+1)}}{(N+1) !} e^{-k t}+A_{1}(0) \frac{(k t)^{N}}{N !} e^{-k t}+\cdots+A_{N}(0) \frac{(k t)}{1 !} e^{-k t} \\
& \begin{array}{lllllllllll}
\vdots & \vdots & + & & \vdots & & + & & + & &
\end{array}
\end{aligned}
$$

This model accounts explicitly for the depletion of a given cluster due to BIRD and/or laser-induced photodissociation as well as its appearance as a product from the next largest cluster. Note that the abundances of clusters with $m=0$ through $N$ have $(m+1)$ terms, and clusters with $m>N$ have $(N+1)$ terms. As long as the abundances $A_{m}(t)$ for large values of $m$ are very small, each row of this system of equations can be weighted by $m$, and their sum approximated by summing from $m=$ 0 to $\infty$ :

$$
\begin{aligned}
\sum_{m=0}^{\infty} m \times A_{m}(t)= & A_{0}(0) \times(k t+0)+A_{1}(0) \times(k t+1) \\
& +\cdots+A_{N}(0) \times(k t+N)
\end{aligned}
$$

Collecting terms involving $k t$ and dividing both sides of this equation by the total abundance of all precursor and product ions $\left(=A_{0}(0)+\ldots+A_{N}(0)\right)$, we obtain

$$
\langle m(t)\rangle=k t+\langle m(0)\rangle
$$

Thus, the initial abundance-weighted average BIRD rate constant $k_{B I R D}$ for an ensemble with an average of $\left(n_{\text {MAX }}-\langle m(0)\rangle\right)$ water molecules is obtained as $(\langle m(t)\rangle-\langle m(0)\rangle) / t$ in the absence of laser irradiation, $k_{I R P D}$ for the laser-irradiated ensemble is obtained as $\left(\left\langle m\left(t_{i r r}\right)\right\rangle-\langle m(0)\rangle\right) / t_{i r r}$, and the ensemble $k_{\text {laser }}$ is simply $\left(k_{\text {IRPD }}-k_{\text {BIRD }}\right)$. Ensemble IRPD spectra thus obtained represent a mass-selected range of precursor sizes of known relative abundance, in contrast to experiments on large neutral water clusters where the distribution of precursor sizes is poorly characterized [81].

It is readily seen that this result reduces to the logarithm-based $k_{\text {laser }}$ described in the Introduction when $N=0$, i.e., when the precursor ensemble consists of a single cluster size. To illustrate this method, the "weighted-average" (WA) IRPD spectrum of isolated $\mathrm{La}^{3+}\left(\mathrm{H}_{2} \mathrm{O}\right)_{36}$ calculated using the same data as for the PDY, depletion, and (logarithm-based) $k_{\text {laser }}$ methods is shown in Figure 3. The IRPD intensities calculated using the WA method are substantially more similar to those using the logarithm-based $k_{\text {laser }}$ method than for the PDY or depletion methods, with essentially identical values for the FWHM of the spectral bands. Indeed, the WA intensities are typically $\sim 90 \% \pm 10 \%$ of the logarithm-based intensities. It is not surprising that the WA intensities are slightly too low, because the BIRD rate constants of $\mathrm{La}^{3+}\left(\mathrm{H}_{2} \mathrm{O}\right)_{n}, n \leq 35$, are typically lower than that for $\mathrm{La}^{3+}\left(\mathrm{H}_{2} \mathrm{O}\right)_{36}$, but this error can be reduced by shortening the irradiation time so as to reduce the range of product cluster sizes. Another feature attributable to the contribution of $\mathrm{La}^{3+}\left(\mathrm{H}_{2} \mathrm{O}\right)_{n}, n \leq 35$, to the WA spectrum is the appearance of a discernable shoulder at $\sim 3694 \mathrm{~cm}^{-1}$, which is not observed as a distinct feature in any of the other IRPD spectra of isolated $\mathrm{La}^{3+}\left(\mathrm{H}_{2} \mathrm{O}\right)_{36}$ but might be expected based on previously reported IRPD spectra of $\mathrm{La}^{3+}\left(\mathrm{H}_{2} \mathrm{O}\right)_{n}, n \leq 17-20$ [47]. This band is likely present in the IRPD spectra of clusters with $n=34$ or 35 , which contribute substantially to the calculation of $k_{\text {laser }}$ using the WA method.

To illustrate the results obtained by the WA method with an ensemble of isolated precursor clusters (the "ensemble IRPD" method), we measured the ensemble IRPD spectrum of the $\mathrm{La}^{3+}\left(\mathrm{H}_{2} \mathrm{O}\right)_{n}, n=35-37$, which is shown in Figure 3. Representative mass spectra of the ensemble $\mathrm{La}^{3+}\left(\mathrm{H}_{2} \mathrm{O}\right)_{35,36,37}$ after initial isolation, $1.5 \mathrm{~s}$ of BIRD, and $1.5 \mathrm{~s}$ of $3694 \mathrm{~cm}^{-1}$ laser-induced photodissociation are shown in Figure 2 (bottom). As with the 
data for the IRPD spectra discussed above, $k_{B I R D}$ in the absence of laser irradiation was re-measured every $\sim 15$ min so as to characterize the variability in $\langle m(0)\rangle$ over the course of spectral acquisition. The average number of water molecules in the precursor ensemble after $1.5 \mathrm{~s}$ of exposure to the $133 \mathrm{~K}$ blackbody field was remarkably constant (35.94 \pm 0.01 water molecules), based on 14 measurements made over the course of spectrum acquisition. The resulting ensemble IRPD spectrum is very similar in shape to the logarithm- and WA-based $k_{\text {laser }}$ spectra for $\mathrm{La}^{3+}\left(\mathrm{H}_{2} \mathrm{O}\right)_{36}$, with very similar FWHMs (within $<10 \%$ ) for the two bands, and the intensity is typically $\sim 85 \%$ of that for the logarithm-based $k_{\text {laser }}$. Because the mass spectral $\mathrm{S} / \mathrm{N}$ was different for the $\mathrm{La}^{3+}\left(\mathrm{H}_{2} \mathrm{O}\right)_{n}$ precursor clusters on the days when the $\mathrm{La}^{3+}\left(\mathrm{H}_{2} \mathrm{O}\right)_{36}$ and $\mathrm{La}^{3+}\left(\mathrm{H}_{2} \mathrm{O}\right)_{35-37}$ ensemble IRPD spectra were measured (see Figure 2), the $\mathrm{S} / \mathrm{N}$ of the corresponding IRPD spectra are not directly comparable.

All of the complexes initially isolated in the ensemble IRPD method contribute to the resulting spectrum, as do the product ions. The resulting ensemble spectrum should therefore reflect the "average" structure of ions within this size range. Thus, structural information deduced from ensemble IRPD spectra as a function of precursor cluster size may better represent general size-related structural trends than IRPD spectra sampling a few individual precursor cluster sizes out of a large range, as has been reported for large protonated water clusters [80] and hydrated $\mathrm{Ca}^{2+}$ clusters [48]. As described above, each of the IRPD spectra for isolated $\mathrm{La}^{3+}\left(\mathrm{H}_{2} \mathrm{O}\right)_{36}$ has a single band from $\sim 3650$ to 3710 $\mathrm{cm}^{-1}$, whereas two distinct features are observed in this spectral range for $\mathrm{La}^{3+}\left(\mathrm{H}_{2} \mathrm{O}\right)_{17-20}$ at $133 \mathrm{~K}$. The free $\mathrm{OH}$ feature at $\sim 3650-3710 \mathrm{~cm}^{-1}$ in the ensemble IRPD spectrum is resolved into two features (centered at 3684 and $3694 \mathrm{~cm}^{-1}$ ), consistent with the previously reported bands due to double hydrogen-bond acceptor/single donor and single acceptor/single donor water molecules observed in hydrated clusters of trivalent lanthanide metal cations with between 17 and 20 water molecules [47]. Evidently, sampling only $\mathrm{La}^{3+}\left(\mathrm{H}_{2} \mathrm{O}\right)_{36}$ to represent structures with $\sim 36$ water molecules could obscure the fact that both types of water molecules are present in other clusters in this size range.

\section{Conclusions}

Several different methods are commonly used to obtain experimental intensities for IRPD spectra, including the photodissociation yield, the depletion/appearance of a precursor/fragment ion, and the first-order laserinduced photodissociation rate constant. For experiments in which multiphoton dissociation is not a major process and for which no induction period occurs in dissociation kinetics, $k_{\text {laser }}(\hbar \omega)$ is preferred because it is the most directly comparable of these values to a linear absorption cross-section and is independent of the irradiation time. An additional advantage is that noninterconverting conformers with unique IRPD spectra can be resolved based on their different dissociation rate constants. We have introduced a new method for obtaining $k_{\text {laser }}(\hbar \omega)$ for ensembles of sufficiently large clusters that reproduces results for $k_{\text {laser }}(\hbar \omega)$ in the case that the ensemble consists of a single precursor cluster size. This method offers additional advantages over other commonly used methods to study the IRPD spectra of large hydrated clusters in that the S/N can be improved without significantly increasing acquisition time, and ensemble IRPD spectra represent typical structures for cluster ions of a well-defined cluster size range and distribution. In a series of forthcoming papers, we will use ensemble IRPD spectroscopy to examine structural trends of much larger hydrated clusters for a variety of ions and cluster sizes.

\section{Acknowledgments}

The authors thank Daniel J. Kennedy for help with data acquisition and the National Science Foundation (grant CHE-0718790) for generous financial support.

\section{References}

1. Oepts, D.; van der Meer, A. F. G.; van Amersfoort, P. W. The FreeElectron-Laser User Facility Felix. Infrared Phys. Technol. 1995, 36, 297-308.

2. Lemaire, J.; Boissel, P.; Heninger, M.; Mauclaire, G.; Bellec, G.; Mestdagh, H.; Simon, A.; Caer, S. L.; Ortega, J. M.; Glotin, F.; Maitre, P. Gas Phase Infrared Spectroscopy of Selectively Prepared Ions. Phys. Rev. Lett. 2002, 89, 4.

3. Eyler, J. R. Infrared Multiple Photon Dissociation Spectroscopy of Ions in Penning Traps. Mass Spectrom. Rev. 2009, 28, 448-467.

4. Bush, M. F.; O'Brien, J. T.; Prell, J. S.; Saykally, R. J.; Williams, E. R. Infrared Spectroscopy of Cationized Arginine in the Gas Phase: Direct Evidence for the Transition from Nonzwitterionic to Zwitterionic Structure. J. Am. Chem. Soc. 2007, 129, 1612-1622.

5. Nizkorodov, S. A.; Maier, J. P.; Bieske, E. J. The Infrared-Spectrum of the $\mathrm{N}_{2} \mathrm{H}^{+}$-He Ion-Neutral Complex. J. Chem. Phys. 1995, 102, 5570-5571.

6. Dryza, V.; Poad, B. L. J.; Bieske, E. J. Spectroscopic Study of the Benchmark $\mathrm{Mn}^{+}-\mathrm{H}_{2}$ Complex. J. Phys. Chem. A 2009, 113, 6044-6048.

7. Gregoire, G.; Velasquez, J.; Duncan, M. A. Infrared Photodissociation Spectroscopy of Small $\mathrm{Fe}^{+}-\left(\mathrm{CO}_{2}\right)_{n}$ and $\mathrm{Fe}^{+}-\left(\mathrm{CO}_{2}\right)_{n} \mathrm{Ar}$ clusters. Chem. Phys. Lett. 2001, 349, 451-457.

8. Kamariotis, A.; Boyarkin, O. V.; Mercier, S. R.; Beck, R. D.; Bush, M. F.; Williams, E. R.; Rizzo, T. R. Infrared Spectroscopy of Hydrated Amino Acids in the Gas Phase: Protonated and Lithiated Valine. J. Am. Chem. Soc. 2006, 128, 905-916.

9. Macleod, N. A.; Simons, J. P. Neurotransmitters in the Gas Phase: Infrared Spectroscopy and Structure of Protonated Ethanolamine. Phys Chem., Chem. Phys. 2004, 6, 2821-2826.

10. Graham, R. J.; Kroemer, R. T.; Mons, M.; Robertson, E. G.; Snoek, L. C. Simons, J. P. Infrared Ion Dip Spectroscopy of a Noradrenaline Analogue: Hydrogen Bonding in 2-Amino-1-Phenylethanol and Its Singly Hydrated Complex. J. Phys. Chem. A 1999, 103, 9706-9711.

11. Bakker, J. M.; Besson, T.; Lemaire, J.; Scuderi, D.; Maître, P. Gas-Phase Structure of a $\pi$-Allyl-Palladium Complex: Efficient Infrared Spectroscopy in a 7 T Fourier Transform Mass Spectrometer. J. Phys. Chem. A 2007, 111, 13415-13424

12. Oh, H. B.; Lin, C.; Hwang, H. Y.; Zhai, H. L.; Breuker, K.; Zabrouskov, V.; Carpenter, B. K.; McLafferty, F. W. Infrared Photodissociation Spectroscopy of Electrosprayed Ions in a Fourier Transform Mass Spectrometer. J. Am. Chem. Soc. 2005, 127, 4076-4083.

13. Sawamura, T.; Fujii, A.; Sato, S.; Ebata, T.; Mikami, N. Characterization of the Hydrogen-Bonded Cluster Ions [phenol- $\left.\left(\mathrm{H}_{2} \mathrm{O}\right)_{n}\right]^{+}(n=1-4)$ $(\text { Phenol })_{2}{ }^{+}$, and (Phenol-Methanol) ${ }^{+}$as Studied by Trapped Ion Infrared Multiphoton Dissociation Spectroscopy of Their OH Stretching Vibrations. J. Phys. Chem. 1996, 100, 8131-8138.

14. Ayotte, P.; Bailey, C. G.; Kim, J.; Johnson, M. A. Vibrational Predissociation Spectroscopy of the $\left(\mathrm{H}_{2} \mathrm{O}\right)_{6}{ }^{-} \cdot \mathrm{Ar}_{n}, n \geq 6$, clusters. J. Chem. Phys. 1998, 108, 444-449.

15. Roscioli, J. R.; Hammer, N. I.; Johnson, M. A. Infrared Spectroscopy of Water Cluster Anions, $\left(\mathrm{H}_{2} \mathrm{O}\right)_{n}=3-24^{-}$in the $\mathrm{HOH}$ Bending Region: Persistence of the Double H-Bond Acceptor (AA) Water Molecule in the Excess Electron Binding Site of the Class I Isomers. J. Phys. Chem. A 2006, 110, 7517-7520. 
16. Pribble, R. N.; Zwier, T. S. Probing Hydrogen-Bonding in Benzene(Water $)_{n}$ Clusters Using Resonant Ion-Dip IR Spectroscopy. Faraday Discuss. 1994, 97, 229-241.

17. Stearns, J. A.; Das, A.; Zwier, T. S. Hydrogen Atom Dislocation in the Excited State of Anthranilic Acid: Probing the Carbonyl Stretch Fundamental and the Effects of Water Complexation. Phys. Chem., Chem. Phys. 2004, 6, 2605-2610.

18. Okumura, M.; Yeh, L. I.; Lee, Y. T. Infrared-Spectroscopy of the Cluster Ions $\mathrm{H}_{3}{ }^{+} \cdot\left(\mathrm{H}_{2}\right)_{n}$. J. Chem. Phys. 1988, 88, 79-91.

19. Wang, Y. S.; Tsai, C. H.; Lee, Y. T.; Chang, H. C.; Jiang, J. C.; Asvany, O.; Schlemmer, S.; Gerlich, D. Investigations of Protonated and Deprotonated Water Clusters Using a Low-Temperature 22-Pole Ion Trap. J. Phys. Chem. A 2003, 107, 4217-4225.

20. Sakota, K.; Kageura, Y.; Sekiya, H. Cooperativity of Hydrogen-Bonded Networks in 7-Azaindole $\left(\mathrm{CH}_{3} \mathrm{OH}\right)_{n}(n=2,3)$ Clusters Evidenced by IR-UV Ion-Dip Spectroscopy and Natural Bond Orbital Analysis. J. Chem. Phys. 2008, 129, 054303.

21. Mahjoub, A.; Chakraborty, A.; Lepere, V.; Le Barbu-Debus, K.; Guchhait, N.; Zehnacker, A. Chirality-Dependent Hydrogen Bond Direction in Jet-Cooled (S)-1,2,3,4-Tetrahydro-3-Isoquinoline Methanol (THIQM): IR-Ion Dip Vibrational Spectroscopy of the Neutral and the Ion. Phys. Chem., Chem. Phys. 2009, 11, 5160-5169.

22. Polfer, N. C.; Oomens, J. Vibrational Spectroscopy of Bare and Solvated Ionic Complexes of Biological Relevance. Mass Spectrom. Rev. 2009, 28, 468-494.

23. Walker, N. R.; Walters, R. S.; Duncan, M. A. Frontiers in the Infrared Spectroscopy of Gas Phase Metal Ion Complexes. New. J. Chem. 2005, 29, 1495-1503.

24. MacAleese, L.; Maître, P. Infrared Spectroscopy of Organometallic Ions in the Gas Phase: From Model to Real World Complexes. Mass Spectrom. Rev. 2007, 26, 583-605.

25. Jockusch, R. A.; Paech, K.; Williams, E. R. Energetics from Slow Infrared Multiphoton Dissociation of Biomolecules. J. Phys. Chem. A 2000, 104, 3188-3196.

26. Freitas, M. A.; Hendrickson, C. L.; Marshall, A. G. Determination of Relative Ordering of Activation Energies for Gas-Phase Ion Unimolecular Dissociation by Infrared Radiation for Gaseous Multiphoton Energy Transfer. J. Am. Chem. Soc. 2000, 122, 7768-7775.

27. Headrick, J. M.; Bopp, J. C.; Johnson, M. A. Predissociation Spectroscopy of the Argon-Solvated $\mathrm{H}_{5} \mathrm{O}_{2}{ }^{+}$" zundel" Cation in the 1000-1900 $\mathrm{cm}^{-1}$ region. J. Chem. Phys. 2004, 121, 11523-11526.

28. Simon, A.; MacAleese, L.; Maître, P.; Lemaire, J.; McMahon, T. B. Fingerprint Vibrational Spectra of Protonated Methyl Esters of Amino Acids in the Gas Phase. J. Am. Chem. Soc. 2007, 129, 2829-2840.

29. Oomens, J.; Tielens, A.; Sartakov, B. G.; von Helden, G.; Meijer, G. Laboratory Infrared Spectroscopy of Cationic Polycyclic Aromatic Hydrocarbon Molecules. Astrophys. J. 2003, 591, 968-985.

30. Prell, J. S.; Demireva, M.; Williams, E. R. Role of Sequence in Salt-Bridge Formation for Alkali Metal Cationized GlyArg and ArgGly Investigated with IRMPD Spectroscopy and Theory. J. Am. Chem. Soc. 2009, 131, 1232-1242.

31. Prell, J. S.; O’Brien, J. T.; Steill, J. D.; Oomens, J.; Williams, E. R. Structures of Protonated Dipeptides: The Role of Arginine in Stabilizing Salt Bridges. J. Am. Chem. Soc. 2009, 131, 11442-11449.

32. Vala, M.; Szczepanski, J.; Oomens, J.; Steill, J. D. $\mathrm{H}_{2}$ Ejection from Polycyclic Aromatic Hydrocarbons: Infrared Multiphoton Dissociation Study of Protonated 1,2-Dihydronaphthalene. J. Am. Chem. Soc. 2009, 131, 5784-5791.

33. Price, W. D.; Schnier, P. D.; Jockusch, R. A.; Strittmatter, E. F.; Williams, E. R. Unimolecular Reaction Kinetics in the High-Pressure Limit Without Collisions. J. Am. Chem. Soc. 1996, 118, 10640-10644.

34. Dunbar, R. C. BIRD (Blackbody Infrared Radiative Dissociation): Evolution, Principles, and Applications. Mass Spectrom. Rev. 2004, 23, 127-158

35. Drayß, M. K.; Blunk, D.; Oomens, J.; Gao, B.; Wyttenbach, T.; Bowers, M. T.; Schäfer, M. Systematic Study of the Structures of Potassiated Tertiary Amino Acids: Salt Bridge Structures Dominate. J. Phys. Chem. A 2009, 113, 9543-9550.

36. Martínez-Haya, B.; Hurtado, P.; Hortal, A. R.; Steill, J. D.; Oomens, J.; Merkling, P. J. Spectroscopic Investigation of the Gas-Phase Conformations of 15-Crown-5 Ether Complexes with $\mathrm{K}^{+}$. J. Phys. Chem. A 2009, 113, 7748-7752

37. Dunbar, R. C.; Steill, J. D.; Polfer, N. C.; Oomens, J. Gas-Phase Infrared Spectroscopy of the Protonated Dipeptides $\mathrm{H}^{+}$PheAla and $\mathrm{H}^{+}$AlaPhe Compared with Condensed-Phase Results. Int. J. Mass Spectrom. 2009, 283, 77-84.

38. Heaton, A. L.; Bowman, V. N.; Oomens, J.; Steill, J. D.; Armentrout, P. B. Infrared Multiple Photon Dissociation Spectroscopy of Cationized Asparagine: Effects of Metal Cation Size on Gas-Phase Conformation. J. Phys. Chem. A 2009, 113, 5519-5530.

39. Leavitt, C. M.; Oomens, J.; Dain, R. P.; Steill, J.; Groenewold, G. S.; van Stipdonk, M. J. IRMPD Spectroscopy of Anionic Group II Metal Nitrate Cluster Ions. J. Am. Soc. Mass Spectrom. 2009, 20, 772-782.

40. Pagel, K.; Kupser, P.; Bierau, F.; Polfer, N. C.; Steill, J. D.; Oomens, J.; Meijer, G.; Koksch, B.; von Helden, G. Gas-Phase IR Spectra of Intact $\alpha$-Helical Coiled Coil Protein Complexes. Int. J. Mass Spectrom. 2009, 283, 161-168.

41. Guidi, M.; Lorenz, U. J.; Papadopoulos, G.; Boyarkin, O. V.; Rizzo, T. R. Spectroscopy of Protonated Peptides Assisted by Infrared Multiple Photon Excitation. J. Phys. Chem. A 2009, 113, 797-799.
42. Vaden, T. D.; de Boer, T. S. J. A.; Simons, J. P.; Snoek, L. C.; Suhai, S.; Paizs, B. Vibrational Spectroscopy and Conformational Structure of Protonated Polyalanine Peptides Isolated in the Gas Phase. J. Phys. Chem. A 2008, 112, 4608-4616.

43. Bush, M. F.; Oomens, J.; Saykally, R. J.; Williams, E. R. Effects of Alkaline Earth Metal Ion Complexation on Amino Acid Zwitterion Stability: Results from Infrared Action Spectroscopy. J. Am. Chem. Soc. 2008, 130, 6463-6471.

44. O'Brien, J. T.; Williams, E. R. Hydration of Gaseous Copper Dications Probed by IR Action Spectroscopy. J. Phys. Chem. A 2008, 112, 58935901.

45. Bush, M. F.; Prell, J. S.; Saykally, R. J.; Williams, E. R. One Water Molecule Stabilizes the Cationized Arginine Zwitterion. J. Am. Chem. Soc. 2007, 129, 13544-13553.

46. Bush, M. F.; Saykally, R. J.; Williams, E. R. Hydration of the Calcium Dication: Direct Evidence for Second Shell Formation from Infrared Spectroscopy. Chem. Phys. Chem. 2007, 8, 2245-2253.

47. Bush, M. F.; Saykally, R. J.; Williams, E. R. Reactivity and Infrared Spectroscopy of Gaseous Hydrated Trivalent Metal Ions. J. Am. Chem. Soc. 2008, 130, 9122-9128.

48. Bush, M. F.; Saykally, R. J.; Williams, E. R. Infrared Action Spectra of $\mathrm{Ca}^{2+}\left(\mathrm{H}_{2} \mathrm{O}\right)_{11-69}$ Exhibit Spectral Signatures for Condensed-Phase Structures with Increasing Cluster Size. J. Am. Chem. Soc. 2008, 130, 1548215489.

49. Prell, J. S.; Williams, E. R. Structures of Thermal, Mass-Selected Water Clusters Probed with Hydrophobic Ion Tags and Infrared Photodissociation Spectroscopy. J. Am. Chem. Soc. 2009, 131, 4110-4119.

50. O'Brien, J. T.; Prell, J. S.; Steill, J. D.; Oomens, J.; Williams, E. R. Changes in Binding Motif of Protonated Heterodimers Containing Valine and Amines Investigated Using IRMPD Spectroscopy between 800 and 3700 $\mathrm{cm}^{-1}$ and Theory. J. Am. Chem. Soc. 2009, 131, 3905-3912.

51. Chiavarino, B.; Crestoni, M. E.; Fornarini, S.; Lanucara, F.; Lemaire, J. Maître, P. Mid-IR Spectroscopy and Structural Features of Protonated Carbonic Acid in the Gas Phase. Chem. Phys. Chem. 2009, 10, 520-522.

52. Fridgen, T. D.; McMahon, T. B.; MacAleese, L.; Lemaire, J.; Maître, P. Infrared Spectrum of the Protonated Water Dimer in the Gas Phase. I. Phys. Chem. A 2004, 108, 9008-9010.

53. Fridgen, T. D.; MacAleese, L.; McMahon, T. B.; Lemaire, J.; Maitre, P. Gas Phase Infrared Multiple-Photon Dissociation Spectra of Methanol, Ethanol, and Propanol Proton-Bound Dimers, Protonated Propanol, and the Propanol/Water Proton-Bound Dimer. Phys. Chem., Chem. Phys. 2006, 8, 955-966.

54. Balaj, O. P.; Kapota, C.; Lemaire, J.; Ohanessian, G. Vibrational Signatures of Sodiated Oligopeptides (GG-Na ${ }^{+}, \mathrm{GGG}^{-\mathrm{Na}^{+}}, \mathrm{AA}-\mathrm{Na}^{+}$, and AAA- $\mathrm{Na}^{+}$) in the Gas Phase. Int. J. Mass Spectrom. 2008, 269, 196-209.

55. Chiavarino, B.; Crestoni, M. E.; Fornarini, S.; Lemaire, I.; MacAleese, L. Maître, P. Infrared Spectroscopy of Protonated Phenylsilane in the Gas Phase. Chem. Phys. Chem. 2005, 6, 437-440.

56. Armentrout, P. B.; Rodgers, M. T.; Oomens, J.; Steill, J. D. Infrared Multiphoton Dissociation Spectroscopy of Cationized Serine: Effects of Alkali-Metal Cation Size on Gas-Phase Conformation. J. Phys. Chem. A 2008, 112, 2248-2257.

57. Dunbar, R. C.; Hopkinson, A. C.; Oomens, J.; Siu, C. K.; Siu, K. W. M.; Steill, J. D.; Verkerk, U. H.; Zhao, J. F. Conformation Switching in Gas-Phase Complexes of Histidine with Alkaline Earth Ions. J. Phys. Chem. B 2009, 113, 10403-10408.

58. Grégoire, G.; Gaigeot, M. P.; Marinica, D. C.; Lemaire, J.; Schermann, J. P.; Desfrançois, C. Resonant Infrared Multiphoton Dissociation Spectroscopy of Gas-Phase Protonated Peptides. Experiments and CarParrinello Dynamics at 300 K. Phys. Chem., Chem. Phys. 2007, 9, 3082 3097.

59. Kong, X. L.; Tsai, I. A.; Sabu, S.; Han, C. C.; Lee, Y. T.; Chang, H. C.; Tu, S. Y.; Kung, A. H.; Wu, C. C. Progressive Stabilization of Zwitterionic Structures in $\left[\mathrm{H}(\mathrm{Ser})_{2-8}\right]^{+}$Studied by Infrared Photodissociation Spectroscopy. Angew. Chem. Int. Ed. 2006, 45, 4130-4134.

60. Rajabi, K.; Fridgen, T. D. Structures of Aliphatic Amino Acid ProtonBound Dimers by Infrared Multiple Photon Dissociation Spectroscopy in the 700-2000 $\mathrm{cm}^{-1}$ region. J. Phys. Chem. A 2008, 112, 23-30.

61. Rodgers, M. T.; Armentrout, P. B.; Oomens, J.; Steill, J. D. Infrared Multiphoton Dissociation Spectroscopy of Cationized Threonine: Effects of Alkali-Metal Cation Size on Gas-Phase Conformation. J. Phys. Chem. A 2008, 112, 2258-2267.

62. Schäfer, M.; Schmuck, C.; Geiger, L.; Chalmers, M. J.; Hendrickson, C. L.; Marshall, A. G. Structurally Related Noncovalent Complexes Examined by Quadrupole Ion Trap (QIT) $\mathrm{MS}^{2}$ and Infrared Multiphoton Dissociation Fourier Transform Ion Cyclotron Resonance Mass Spectrometry IRMPD-FT-ICR MS: Evidence for Salt-Bridge Structures in the Gas Phase. Int. J. Mass Spectrom. 2004, 237, 33-45.

63. Stearns, J. A.; Seaiby, C.; Boyarkin, O. V.; Rizzo, T. R. Spectroscopy and Conformational Preferences of Gas-Phase Helices. Phys. Chem., Chem. Phys. 2009, 11, 125-132.

64. Vaden, T. D.; de Boer, T. S. J. A.; Simons, J. P.; Snoek, L. C. Intramolecular Interactions in Protonated Peptides: $\mathrm{H}^{+}$PheGlyGly and $\mathrm{H}^{+}$GlyGlyPhe. Phys. Chem., Chem. Phys. 2008, 10, 1443-1447.

65. Walters, R. S.; Pillai, E. D.; Duncan, M. A. Solvation Dynamics in $\mathrm{Ni}^{+}\left(\mathrm{H}_{2} \mathrm{O}\right)_{n}$ Clusters Probed with Infrared Spectroscopy. J. Am. Chem. Soc. 2005, 127, 16599-16610.

66. Oomens, J.; van Roij, A. J. A.; Meijer, G.; von Helden, G. Gas-Phase Infrared Photodissociation Spectroscopy of Cationic Polyaromatic Hydrocarbons. Astrophys. J. 2000, 542, 404-410. 
67. Bush, M. F.; Forbes, M. W.; Jockusch, R. A.; Oomens, J.; Polfer, N. C.; Saykally, R. J.: Williams, E. R. Infrared Spectroscopy of Cationized Lysine and $\varepsilon$-N-Methyllysine in the Gas Phase: Effects of Alkali-Metal Ion Size and Proton Affinity on Zwitterion Stability. J. Phys. Chem. A 2007, 111, 7753-7760.

68. Drayss, M. K.; Blunk, D.; Oomens, J.; Schäfer, M. Infrared Multiple Photon Dissociation Spectroscopy of Potassiated Proline. J. Phys. Chem. A 2008, 112, 11972-11974.

69. Dunbar, R. C.; Polfer, N. C.; Oomens, J. Gas-Phase Zwitterion Stabilization by a Metal Dication. J. Am. Chem. Soc. 2007, 129, 14562-14563.

70. Dunbar, R. C.; Steill, J. D.; Polfer, N. C.; Oomens, J. Peptide Length, Steric Effects, and Ion Solvation Govern Zwitterion Stabilization in Barium-Chelated Di- and Tripeptides. J. Phys. Chem. B 2009, 113, 10552-10554.

71. Dunbar, R. C.; Steill, J. D.; Polfer, N. C.; Oomens, J. Dimeric Complexes of Tryptophan with $\mathrm{M}^{2+}$ Metal Ions. I. Phys. Chem. A 2009, 113, 845-851.

72. Forbes, M. W.; Bush, M. F.; Polfer, N. C.; Oomens, J.; Dunbar, R. C. Williams, E. R.; Jockusch, R. A. Infrared Spectroscopy of Arginine Cation Complexes: Direct Observation of Gas-Phase Zwitterions. J. Phys. Chem. A 2007, 111, 11759-11770.

73. O'Brien, J. T.; Prell, J. S.; Steill, J. D.; Oomens, J.; Williams, E. R. Interactions of Mono- and Divalent Metal Ions with Aspartic and Glutamic Acid Investigated with IRMPD Spectroscopy and Theory. J. Phys. Chem. A 2008, 112, 10823-10830.

74. Polfer, N. C.; Paizs, B.; Snoek, L. C.; Compagnon, I.; Suhai, S.; Meijer, G.; von Helden, G.; Oomens, J. Infrared Fingerprint Spectroscopy and
Theoretical Studies of Potassium Ion Tagged Amino Acids and Peptides in the Gas Phase. J. Am. Chem. Soc. 2005, 127, 8571-8579.

75. Wu, R.; McMahon, T. B. IRMPD Spectra of Gly $\cdot \mathrm{NH}_{4}{ }^{+}$and ProtonBound Betaine Dimer: Evidence for the Smallest Gas Phase Zwitterionic Structures. J. Mass Spectrom. 2008, 130, 3065-3078.

76. $\mathrm{Wu}, \mathrm{R}$. H.; McMahon, T. B. Infrared Multiple Photon Dissociation Spectra of Proline and Glycine Proton-Bound Homodimers. Evidence for Zwitterionic Structure. J. Am. Chem. Soc. 2007, 129, 4864-4865.

77. Steill, J. D.; Oomens, J. Gas-Phase Deprotonation of p-Hydroxybenzoic Acid Investigated by IR Spectroscopy: Solution-Phase Structure Is Retained Upon ESI. J. Am. Chem. Soc. 2009, 131, 13570-13571.

78. Wong, R. L.; Paech, K.; Williams, E. R. Blackbody Infrared Radiative Dissociation at Low Temperature: Hydration of $\mathrm{X}^{2+}\left(\mathrm{H}_{2} \mathrm{O}\right)_{n}$, for $\mathrm{X}=\mathrm{Mg}$, Ca. Int. J. Mass Spectrom. 2004, 232, 59-66.

79. Shin, J. W.; Hammer, N. I.; Diken, E. G.; Johnson, M. A.; Walters, R. S.; Jaeger, T. D.; Duncan, M. A.; Christie, R. A.; Jordan, K. D. Infrared Signature of Structures Associated with the $\mathrm{H}^{+}\left(\mathrm{H}_{2} \mathrm{O}\right)_{n}(n=6-27)$ Clusters. Science 2004, 304, 1137-1140.

80. Mizuse, K.; Fujii, A.; Mikami, N. Long Range Influence of an Excess Proton on the Architecture of the Hydrogen Bond Network in LargeSized Water Clusters. J. Chem. Phys. 2007, 126, 231101.

81. Steinbach, C.; Andersson, P.; Kazimirski, J. K.; Buck, U.; Buch, V. Ben, T. A. Infrared Predissociation Spectroscopy of Large Water Clusters: A Unique Probe of Cluster Surfaces. J. Phys. Chem. A 2004 108, 6165-6174. 